\title{
Semiconducting Poly (1-Aminoanthroquinone) Nanoscale Materials: Synthesis, Morphological Aspects and Novel Catalytic Applications
}

\section{Sakthivel}

Bharathiar University School of Chemical Sciences

\section{A. Nivetha}

Bharathiar University School of Chemical Sciences

C. Suresh Philip

Bharathiar University School of Chemical Sciences

PRABHA I ( $D$ iprabha2007@gmail.com )

Bharathiar University School of Chemical Sciences

\section{Research Article}

Keywords: Biphasic, Carbon dioxide, Polymer, Nanoscale, Eradication, Catalytic renovation

Posted Date: August 23rd, 2021

DOI: https://doi.org/10.21203/rs.3.rs-811859/v1

License: (9) This work is licensed under a Creative Commons Attribution 4.0 International License. Read Full License 


\section{Abstract}

The intrinsic semiconducting poly (1-aminoanthraquinone) (PAAQ) was synthesized by simple oxidative polymerization of 1-aminoanthraquinone (1-AAQ) as a starting monomer at 25,40 and $50{ }^{\circ} \mathrm{C}$ in the biphasic system. In this study $70 \%$ of perchloric acid $\left(\mathrm{HClO}_{4}\right)$ was used to enhance the acidity and $30 \%$ of hydrogen peroxide was acted as an oxidant. The synthesized polymers were undergone studies for their crystalline nature, surface morphology, optical behavior, and electrochemical potential using XRD, SEM, UV-Vis, Fluorescence, FT-IR, DLS, and CV techniques respectively. The average crystalline size were found to be 45.47, 45.88, $45.51 \mathrm{~nm}$ and its band gap energies were 3.95, 3.89, 3.70, $3.55 \mathrm{eV}$ at 25, 40 and $50{ }^{\circ} \mathrm{C}$ respectively. The SEM images reveal the formation of well-defined nanocubes with sheets and the average particles size was $75 \mathrm{~nm}$. The efficiency in electrochemical properties of synthesized PAAQ polymerare evident from its redox peaks and in impedance curve. The synthesized PAAQ polymer at $25^{\circ} \mathrm{C}$ have showed an optimized catalytic conversion of $\mathrm{CO}_{2}$ to $\mathrm{CO}_{3}$ and the stabilized shielding property against X-Ray irradiation during radiation therapy.

\section{Introduction}

In the recent trends, the researcher's intense focus is on the synthesis of organic polymer which contains heterocyclic and polycyclic aromatic or non-aromatic hydrocarbons contain multifunctional groups such as heteroatoms, amino and hydroxyl groups with enhanced new physic-chemical properties. Hence it could be used in super-capacitors, sensors, batteries, chemical conversion, electro and photo-catalysis, fabrication of optoelectronic devices etc [1]. There have limited research works been employed with amino-anthraquinone (AAQ) and its derivatives, as this monomer is soluble only in high polar solvents like acetonitrile, dimethyl sulfoxide (DMSO), and dimethyl formamide (DMF) in an acidic medium [2]. In the past decade, it was established that polyaniline (PANI) exhibited a remarkable property on electrical conductivity, optical activity, heavy metal removal, electro-catalysis, environmental remediation etc. Poly (1, 5-diaminoanthraquinone) and poly (2-aminoanthraquinone) also exhibited the excellent properties such as stable electro-activity, specific electro-capacity and reversible redox potential. Therefore, it is expected that poly (1-aminoanthraquinone) would also exhibit better performance on high electrical conductivity due to the presence of 1,4-benzoquinone moiety to produce high electro-activity. As poly(1aminoanthraquinone) is a higher sensitive polymer than PANI, a special effort was taken to choose suitable solvents and solution medium for its of high purity [3-4].

A huge quantity of carbon dioxide has been released by volcanic eruption, motor vehicles and factories etc. Since carbon dioxide is heavier than oxygen it spreads widely and pollutes the atmosphere which causes scarcity of fresh oxygen leading to health and environment related problems. In the present scenario, capturing and conversion of carbon dioxide into useful products for societal based which makes high impacts. The research works are done with zeolites, mesoporous $\mathrm{SiO}_{2}$, metal organic frameworks (MOFs) and organic polymers etc used for the absorption of $\mathrm{CO}_{2}$ [5]. Notably, the present research work emphazise on PAAQ as a catalyst for the conversion of carbon dioxide into carbonate 
through chemical reaction. It is emerging, required to work out and conquer the problems via capturing or conversion of through PAAQ with low cost material in easy monitoring process.

Cancer is a life threatening deadly disease which could not be cured completely with $100 \%$ accuracy due to the lack of medicine and treatment methodology. X-ray-induced photodynamic therapy (X-PDT) and radiation therapy are the promising techniques to treat the affected tumors. It is effectively penetrated into cell and generates the reactive oxygen species (ROS) to cure or shrinking the size of the cancer cells. These techniques still considerable but not completely cure the cancer. The radiation therapy is not only kill the tumor cells but also affect the neighboring healthy cells too. Hence it is needed to improve the efficiency of the techniques to resolve the difficulties [6-7]. It has revealed that the PAAQ has been interestingly and newly used in the field of X-rays due to the negligible side effects. The superfluous radiation can be absorbed or controlled via polymer thin film coated chamber around in X-rays irradiation.

The present work clearly describes the synthesis, structural properties and applications of poly(1aminoanthraquinone). It was successfully synthesized by chemical oxidative polymerization with high productivity and molecular weight, good self-stability, high conducting carbon ratio, thermal stability, cost effectiveness, environment friendly and purity etc.

\section{Experimentation \\ 2.1 Chemicals}

1-aminoanthraquinone (1-AAQ), $70 \%$ perchloric acid $\left(\mathrm{HClO}_{4}\right)$, Acetonitrile $\left(\mathrm{CH}_{3} \mathrm{CN}\right), 30 \%$ Hydrogen peroxide $\left(\mathrm{H}_{2} \mathrm{O}_{2}\right)$ and ethanol $\left(\mathrm{C}_{2} \mathrm{H}_{5} \mathrm{OH}\right)$ were purchased from Sigma Aldrich with high purity. Carbonated water (sparkling water) was purchased from grocery supermarket, Coimbatore, India. Double distilled water was used throughout the experiments.

\subsection{Synthesis of poly(1-aminoanthraquinone)}

Poly(1-aminoanthraquinone) was prepared by simple oxidative polymerization is shown in Figure.1.Accurately weighed $0.446 \mathrm{mg}(2 \mathrm{mmol})$ of 1-aminoanthraquinone was taken into $100 \mathrm{~mL} \mathrm{RB}$ flask containing $40 \mathrm{~mL}$ of acetonitrile $\left(\mathrm{CH}_{3} \mathrm{CN}\right)$ in water bath at $25^{\circ} \mathrm{C}$ and kept stirring for $15 \mathrm{~min}$. $1020.15 \mu \mathrm{L}(11.8 \mathrm{M})$ of $70 \%$ perchloric acid was added drop wise with constant stirring for $45 \mathrm{~min}$ to obtain the homogeneous solution. $30 \%$ hydrogen peroxide $\left(\mathrm{H}_{2} \mathrm{O}_{2}\right)$ was prepared by mixing $0.2042 \mu \mathrm{L}$ (2 $\mathrm{mmol}$ ) in $1 \mathrm{~mL}$ of DI water to obtain oxidant solution. It was added to the parent mixture by the rate of 60 $\mu \mathrm{L}$ for every $5 \mathrm{sec}$ and allowed to stir continuously for $72 \mathrm{hrs}$ at $25^{\circ} \mathrm{C}$. The resulting solution was isolated from reaction mixture by the process of centrifuging. The proposed mechanism for the synthesis of poly(1-aminoanthraquinone) is shown in scheme.1.

The obtained precipitate was washed with ethanol to remove the oxidant, un-reacted monomer and soluble oligomers etc. It was dried at $50^{\circ} \mathrm{C}$ for 3 days in a hot air oven to attain the poly(1- 
aminoanthraquinone) as dark-brown powder which should be stored at ambient condition. The same procedure for the synthesis of PAAQ was repeated at 40 and $50^{\circ} \mathrm{C}$.

\subsection{Analytical techniques}

The crystalline size of PAAQ was determined by X-ray powder diffraction (XRD) at room temperature on a PANalyticalX'pert PRO X-ray diffractometer with Cu-Karadiation $(\lambda=1.5406 \AA)$ as the X-ray resource. FT-IR study was obtained at $4000-400 \mathrm{~cm}^{-1}$ using the pellets of KBr by JASCO FT/IR-4100 spectrometer with the resolution of $1 \mathrm{~cm}^{-1}$. The optical band gap was predicted from JASCO V-630 UV-Vis spectrophotometer. The fluorescence emission and excitation spectra were obtained by FP-8300 fluorescence spectrophotometer made by JASCO spectro-fluorometer. The morphology was examined by JEM-2010F Field Emission Transmission Electron Microscope (200 kV). Cyclic Voltammetry and AC impedance (EIS-Electrochemical Impedance Spectroscopy) were done by $\mathrm{CH}$ device 660 of electrochemical analyzer. The electrochemical working electrodes were prepared using active materials, carbon black and polyvinyl difluoride (PVDF) as a binder with the ratio of 85:10:05. Three dissimilar electrodes such as Ag/AgClas reference, platinum as counter electrode and synthesized PAAQ as an activated material. The $\mathrm{CV}$ and $\mathrm{AC}$ impedance (EIS) experiments were proved using $1 \mathrm{M}$ sulphuric acid as an electrolyte. Accurately weighed $42.5 \mathrm{mg}$ of PAAQ was coated on graphite sheet with $5 \mathrm{mg}$ of polyvinyl difluoride (PVDF) as a binder. $2.5 \mathrm{mg}$ of carbon black with required amount of dimethyl formamide was used to make slurry and coated on the graphite sheet of $1 \mathrm{~cm} \times 1 \mathrm{~cm}$ square to act as a functioning electrode. Finally, the prepared working electrode was dried at $80^{\circ} \mathrm{C}$ for $2 \mathrm{~h}$ for further analysis.

\subsection{Determination of Electrical conductivity}

The electrical conductivity was determined using Multi-Parameter PCS Tester (Eutech PCSTEST3501X441506/Oakton 35425-10). The electrical conductivity measurements were carried out for polymer solution and it was prepared by dissolving $15 \mathrm{mg}$ of assynthesized polymer sample in $30 \mathrm{~mL}$ of acetonitrile and sonicated for 30 min to obtain homogeneous solution. It was use for further analysis.

\subsection{Catalytic conversion study}

The conversion of $\mathrm{CO}_{2}$ to $\mathrm{CO}_{3}$ was done using as-synthesized PAAQ polymer at $25^{\circ} \mathrm{C}$ as a catalyst. In this study, $10 \mathrm{~mL}$ of carbonated water and $2 \times 10^{-3}$ of sodium hydroxide was dissolved in $100 \mathrm{~mL}$ of RB flask, stirred for $15 \mathrm{~min}$ at room temperature and kept without any disturbance. Accurately weighed 10 mg of PAAQ at $25^{\circ} \mathrm{C}$ was dissolved in $5 \mathrm{~mL}$ of acetonitrile $\left(\mathrm{CH}_{3} \mathrm{CN}\right)$ and it was shaken completely till it gets dissolved. It was added slowly into the reaction mixture and was taken in $3.5 \mathrm{~mL}$ of UV cuvette with closed top for the completion of process. The catalytic conversion was examined by UV-Vis spectroscopy with respect to different time intervals from 0 to $20 \mathrm{~min}$. During the reaction, the $\mathrm{pH}$ of the mixture was monitored periodically. The catalytic conversion of $\mathrm{CO}_{2}$ to $\mathrm{CO}_{3}$ using PAAQ at $25^{\circ} \mathrm{C}$ is shown in Figure.2.

\section{Results And Discussion}




\subsection{Appropriateness of optimum conditions for the synthesis of PAAQ}

The optimum conditions such as selection of key solvent, oxidant and temperature were the most essential for the synthesis of poly-1-aminoanthraquinone [5]. The high polar solvents like methyl formamide (DMF), dimethyl sulfoxide (DMSO), dinitrobenzene $\left(\mathrm{C}_{6} \mathrm{H}_{4} \mathrm{~N}_{2} \mathrm{O}_{4}\right)$, dichlorobenzene $\left(\mathrm{C}_{6} \mathrm{H}_{4} \mathrm{Cl}_{2}\right)$, and trichloromethane $\left(\mathrm{CHCl}_{3}\right)$ which were used as the effective solvents for liquefaction of starting monomers [8]. During the synthesis, acetonitrile was used for increasing the solubility of 1-AAQ monomers. $70 \%$ of perchloric acid was used to increase the acidic nature of monomers for effective polymerization process. Poor solubility of monomers and oxidants in same solvent has reduced the productivity of polymer and there is a chance of lesser amount of water which could hinder the process. The confirmation of biphasic system of acetonitrile and $70 \%$ perchloric acid have enhanced the nature of 1-AAQ monomer to undergo polymerization successfully. The oxidants are having standard reduction potential values and the decreasing order of reduction potentials are shown below.

High reduction potential of the oxidant has led to enhance the polymerization and increase the productivity with low reduction potential oxidant vice versa. This experiment was done by high reduction potential oxidant of hydrogen peroxide with high yield of PAAQ [9]. The polymerization of monomer also depends upon the temperature as one of the parameters. The reaction has showed high productivity and utmost purity of PAAQ at $25^{\circ} \mathrm{C}$. At 40 and $50^{\circ} \mathrm{C}$ there was adistortion in shape and size of the formed polymers by slow polymerization with the termination of polymer chain. The OCP $(\mathrm{mV})$, polymerization yield (\%), colour, band gap (eV), surface morphology, redox potential $(\mathrm{V})$, resistance $(\Omega)$ and particle size $(\mathrm{nm})$ of synthesized PAAQ is shown in Table.1. 
Table 1

Characterization results of synthesized PAAQ

\begin{tabular}{|c|c|c|c|c|c|}
\hline S.No & Parameters & $\begin{array}{l}\text { 1-AAQ } \\
\text { monomer }\end{array}$ & $\begin{array}{l}\text { PAAQ at } \\
25^{\circ} \mathrm{C}\end{array}$ & $\begin{array}{l}\text { PAAQ at } \\
40^{\circ} \mathrm{C}\end{array}$ & $\begin{array}{l}\text { PAAQ at } \\
50^{\circ} \mathrm{C}\end{array}$ \\
\hline Solvent & - & Acetonitrile & & & \\
\hline 2. & Oxidant & - & $30 \% \mathrm{H}_{2} \mathrm{O}_{2}$ & & \\
\hline 3. & Biphasic medium & - & $70 \% \mathrm{HClO}_{4} / \mathrm{H}_{2} \mathrm{O}$ & & \\
\hline 4. & $\begin{array}{l}\text { Open Circuit } \\
\text { Potential OCP } \\
(\mathrm{mV})\end{array}$ & 0.0299 & 0.0266 & 0.0340 & 0.0388 \\
\hline 5. & Yield (\%) & - & 53 & 69 & 76 \\
\hline 6. & Colour & Red & $\begin{array}{l}\text { Brownish } \\
\text { Black }\end{array}$ & Brown & Brown \\
\hline 7. & $\begin{array}{l}\text { Band Gap Energy } \\
(\mathrm{eV})\end{array}$ & 3.95 & 3.89 & 3.70 & 3.55 \\
\hline 8. & $\begin{array}{l}\text { Average crystalline } \\
\text { size (nm) }\end{array}$ & 45.60 & 45.47 & 45.88 & 45.51 \\
\hline 9. & $\begin{array}{l}\text { Surface } \\
\text { Morphology }\end{array}$ & $\begin{array}{l}\text { Smooth } \\
\text { Nanorods }\end{array}$ & $\begin{array}{l}\text { Well defined } \\
\text { Nanocubes with } \\
\text { sheets }\end{array}$ & $\begin{array}{l}\text { Irregular } \\
\text { nanocrystals }\end{array}$ & $\begin{array}{l}\text { Cluster of } \\
\text { Nanocrystals }\end{array}$ \\
\hline 10. & Particle size (nm) & 115 & 75 & 72 & 80 \\
\hline 11. & $\begin{array}{l}\text { Redox Potential } \\
\text { (V) }\end{array}$ & $\begin{array}{l}0.1,0.4 \& \\
-0.1,0.3\end{array}$ & $0.2 \&-0.2$ & $\begin{array}{l}0.2,0.4 \& \\
-0.2,0.2\end{array}$ & $\begin{array}{l}-0.1,0.2 \& \\
-0.2,0.2\end{array}$ \\
\hline 12. & Resistance $(\Omega)$ & 7.7 & 8.8 & 15 & 15 \\
\hline
\end{tabular}

\subsection{FT-IR spectral studies}

The FT-IR spectral studies of synthesized PAAQ at 25,40 and $50^{\circ} \mathrm{C}$ are shown in Figure. 3. 1-AAQ monomer exhibits two strong absorption peaks at 3431 and $3310 \mathrm{~cm}^{-1}$ for $-\mathrm{NH}_{2}$ group stretching vibration respectively. During the process the $-\mathrm{NH}_{2}$ group stretching vibration band has got converted successfully into $-\mathrm{NH}$ - group. There was a peak revealed at $1612 \mathrm{~cm}^{-1}$ is due to the presence of contribution of $C=O$ stretching vibration of quinone group. PAAQ bands obtained at $3445 \mathrm{~cm}^{-1}$ describes the $-\mathrm{NH}$ - group stretching vibration and a band at $1646 \mathrm{~cm}^{-1}$ is due to the presence of $\mathrm{C}=0$ stretching vibration of quinone group. The two narrow bands have occurred at 1538 and $1460 \mathrm{~cm}^{-1}$ which correlate to in-plane vibration of structural framework containing of quinoid and benzenoid rings respectively. The presence of a narrow peak at $1277 \mathrm{~cm}^{-1}$ is owing to the contribution of $\mathrm{C}-\mathrm{N}$ stretching vibration. A wide 
range of bands have revealed in between 1145 to $1070 \mathrm{~cm}^{-1}$ is linked to in-plane deformation vibration of $\mathrm{C}-\mathrm{H}$ bond and two miniature bands have occurred at 1460 and $713 \mathrm{~cm}^{-1}$ is related to $\mathrm{C}=\mathrm{C}$ banding vibration and $\mathrm{C}-\mathrm{H}$ out-plane bending vibration. Hence the identified bands were clearly explained the stretching, bending, in-plane deformation and out-plane vibrations during the synthesis process successfully. Finally FT-IR spectral investigation has confirmed the completion of polymerization reaction and the formation of poly(1-aminoanthraquinone).

\subsection{UV-Vis spectral studies}

In UV-Vis spectral studies the PAAQ was dissolved in acetonitrile and a Tauc plot for the determination of band gap energy in normal condition are shown in Figure. 4. Monomer has shown three different absorption bands at 237, 306 and $466 \mathrm{~nm}$ respectively for different energy level transitions such as $\pi-\pi^{*}$ and $n-\pi^{*}$ obtained by functional groups. Basically, polymer has not showed exactly the same absorption bands with different solvents and oxidants. Hence PAAQ was obtained by the presence of acetonitrile as solvent and hydrogen peroxide as an oxidant. The obtained UV-Vis absorption bands were not similar with 1-AAQ. The synthesized PAAQ has shown strong absorption band at $248 \mathrm{~nm}$ related to $\pi-\pi^{*}$ electronic transition due to the presence of benzene rings. The high absorption band was achieved at 318 $\mathrm{nm}$ to confirm the initiation of polymerization of amine groups and broad absorption curve was occurred at $466 \mathrm{~nm}$ which associates with $n-\pi^{*}$ electronic transition. The starting material consists moiety of anthraquinone and shows strong absorption band at $388 \mathrm{~nm}$ by quinone group. In addition to that the 1AAQ and PAAQ polymers were obtained the band gap energies found to be at 3.95, 3.89, 3.70 and 3.55 eVfor 25,40 and $50^{\circ} \mathrm{C}$ respectively. Hence it is concluded that the synthesized polymers have an excellent semiconducting property due the presence of band gap energy results agree with semiconducting range of band gap shown in Fig. 4 (b). The semi-conductivity could be strengthening while rising the temperatures from 25 to $50^{\circ} \mathrm{C}$ confirmed by the electrical conductivity experiment for the polymer samples. Hence UV-Vis spectra have confirmed that the formed polymer at $25^{\circ} \mathrm{C}$ is shown good productivity as well as purity.

\section{Electrical properties of polymer samples}

The electrical conductivity of PAAQ polymers were measured with fixed weight of concentration of samples. The blank solvent of acetonitrile, 1-AAQ monomer and PAAQ polymers were undergone the studies of electrical conductivity, TDS (Total Dissolved Solids) and salinity. Based on the experimental results the electrical conductivity of PAAQ polymers are increased with increase of synthesis temperatures. The TDS and salinity test are the most important parameters to determine the amount of dissolved solids and salts for the respective polymer solution and useful to correlate with EC values (Electrical Conductivity). The correlation between TDS, salinity and EC values was clearly depicted that the obtained values increased with respect to the temperature increasing from 25 to $50^{\circ} \mathrm{C}$. Therefore, the dissolved solids and salts present in the polymer solution are highly responsible for the increase of electrical conductivity [10]. 
Figure 5 predicts the graphical representation of (a) Electrical conductivity (b) TDS and (c) Salinity of PAAQ at $25^{\circ} \mathrm{C}$. From the electrical conductivity it is concluded that the decrease of band gap energy has led to the increase of electrical conductivity respectively and they are inversely proportional. From the graph it has found that the effect of acetonitrile is represented by straight line confirms that there is no change. When the temperature was increased upto $25^{\circ} \mathrm{C}$ there is a sudden increase of electrical conductivity, TDS as well as salinity effectively. After $25^{\circ} \mathrm{C}$ there is gradual raise up in the bar followed by sudden increase of electrical conductivity for polymer sample at $50^{\circ} \mathrm{C}$. The obtained results are given in the Table.2. The values are highly agreed with the band gap energy of synthesized polymer materials using UV studies.

Table 2

Electrical conductivity, TDS and salinity values

\begin{tabular}{|c|c|c|c|c|c|}
\hline S.No & Materials & Catalyst Weight & Electrical Conductivity ( $\mu S$ ) & $\begin{array}{l}\text { TDS } \\
\text { (ppm) }\end{array}$ & $\begin{array}{l}\text { Salinity } \\
\text { (ppm) }\end{array}$ \\
\hline 1. & Acetonitrile (bare) & $30 \mathrm{~mL}$ & 1.3 & 0.5 & 0.0 \\
\hline 2. & 1-AAQ & $15 \mathrm{mg}$ & 2.2 & 1.6 & 12.6 \\
\hline 3. & PAAQ $-25^{\circ} \mathrm{C}$ & & 403 & 286 & 194 \\
\hline 4. & PAAQ $-40^{\circ} \mathrm{C}$ & & 456 & 324 & 221 \\
\hline 5. & PAAQ $-50^{\circ} \mathrm{C}$ & & 572 & 405 & 277 \\
\hline
\end{tabular}

\subsection{Fluorescence effects}

Figure 6 shows the emission and excitation spectra of 1-AAQ monomer and PAAQ. From the spectral evidence it has concluded that 1-AAQ is obtained a strong emission and excitation peaks at 600 and 592 $\mathrm{nm}$ respectively. PAAQ has exhibited emission and excitation bands at 585 and $467 \mathrm{~nm}$ respectively due to the presence of quinone and benzenoid rings in the polymers after the formation process. Stokes shift band maxima was obtained in between the absorption and emission peaks at 118 for PAAQ polymers and $8 \mathrm{~nm}$ for 1-AAQ. The obtained excitation spectrum has showed a strong band at $467 \mathrm{~nm}$ for anthraquinone moiety for the synthesized polymer found to be $\pi \rightarrow \pi^{\star}$ electronic transition [9]. The polymerization was carried out successfully at the optimized temperatures but differed only in the binding interaction. It is due to the loss of energy released by the synthesized polymer which is identified by emission spectrum. And the radioactive decay of excitons has appropriate evident vibronic transitions with emission peak at $585 \mathrm{~nm}$ is due to the presence of orange-light emitting property of PAAQ. It was the amalgamation of charges in the fluorescent intensity which observes the wavelength, intensity and shape of the PAAQ different from 1-AAQ [11].

\subsection{Dynamic Light Scattering (DLS) study}

The DLS study has described the hydrodynamic particle size distribution and surface charge of the PAAQ respectively. Figure 7 (a-d) shows the hydrodynamic average particle size distribution of 1-AAQ and PAAQ 
at 25,40 and $50^{\circ} \mathrm{C}$. The average particle size was calculated to be $295 \pm 5.2,628 \pm 15.3,254 \pm 10.5$ and $138.3 \pm 4.5 \mathrm{~nm}$ for $1-\mathrm{AAQ}$ and PAAQ polymers respectively. From the DLS study it is concluded that the increase of particle size from $628-138$ is due to the presence of increase of temperature at 25,40 and $50^{\circ} \mathrm{C}$ during the polymerization reaction processes [12].

\subsection{X-ray Diffractogram analysis}

The results of X-ray diffraction study of polymer confirm the successful formation and average crystalline size of the synthesized nanopolymers. Figure 8 shows the $X$-ray diffractograms of 1-AAQ and PAAQ at 25,40 and $50^{\circ} \mathrm{C}$. The obtained diffraction peaks of PAAQ were slightly different from 1-AAQ because of high oxidative polymerization process. Hence, PAAQ and 1-AAQ have obtained two high intensitic diffraction peaks at 24.48 and $25.67^{\circ}$ and two weak diffraction peaks at 13.64 and $17.83^{\circ}$ respectively. The obtained diffraction peaks at 13.64 and $25.67^{\circ}$ were attributed to similar main chain like polyaniline [13]. The average crystalline sizes of the synthesized PAAQ polymers with different temperatures have found to be $45.47,45.88$ and $45.51 \mathrm{~nm}$ respectively. From the XRD result it has revealed that the increase of polymerisation temperature from 25 to $50^{\circ} \mathrm{C}$ exhibited the high crystalline structure with low molecular weight and shorter polymer chains respectively. Based on the XRD results, there is low crystalline or squat amorphous nature of the synthesized polymer material which was obtained at $25^{\circ} \mathrm{C}$. While increasing the temperature from 25 to $40^{\circ} \mathrm{C}$ the nature of the amorphous is started increasing and led to the highest amorphous in nature. After $40^{\circ} \mathrm{C}$ the nature of the polymer material has got converted from amorphous to pure crystalline in nature. Hence the high crystalline PAAQ was obtained at $50^{\circ} \mathrm{C}$ and the purity of the synthesized polymer material was exhibited effectively at $25^{\circ} \mathrm{C}$. There is a slight change in the crystallite size of the three synthesized polymer samples when comparing with 1-AAQ monomer due to the indication of zero effect of nanoconfinement in terms of crystallite size (REF). The average crystalline size can be calculated by usingDebye Scherer formula is shown below.

$$
D=\lambda / \beta \cos \theta
$$

Where $D$ is the diameter of grain size $(\AA), \beta$ is the full with half maximum (FWHM) ofthe corresponding peak in radians, $\theta$ is the Braggs angle and $\lambda(1.5405 \AA)$ is the wavelength of $X$-rays used.

\subsection{SEM analysis}

Nanostructuresof semiconducting polymers have prepared through conventional micro-emulsion and dispersion polymerization with necessary modifiers/emulsifiers. This work has done with simple and environmental friendly method like oxidative polymerization with acidic biphasic nature without any external modifiers/ emulsifiers [14]. Figure 9 shows the SEM images of 1-AAQ and PAAQ with different temperatures at acidic medium. 
It is concluded that the temperatures from $25-50^{\circ} \mathrm{C}$ have highly influenced the structural morphology of PAAQ polymers. The synthesized PAAQ polymers formed with very good structural morphology and low average particles in the range of nanoscale. The particles size histogram is calculated through using Image $\mathrm{J}$ tool. It has exhibited the unique electrochemical behaviour and the phenomenal redox potential values which agree with Cyclic Voltammetry (CV) results. When increasing of reaction temperature from 25 to $50^{\circ} \mathrm{C}$, the polymers product obtained as low crystalline respectively. The distorted surface morphology may be the reason for the formation of some oligomers and breaking of polymer chains during the polymerization reaction. Figure 9. (a-c) reveals the neat and uniform nanorods like morphology which are arranged on the polymer surface and their average particles size was found to be $115 \mathrm{~nm}$ and its histogramis shown in Fig. 9. (d).

Figure. $9(\mathrm{e}-\mathrm{g})$ reveals that the formed PAAQ polymers impose the nanocubes with sheets on the polymer surface and the average particles size was found to be $75 \mathrm{~nm}$ for $25^{\circ} \mathrm{C}$ and its histogramis shown in Fig. 9. (h). Figure 9. (i-k) shows the image of polymer obtained at $40^{\circ} \mathrm{C}$ revealing the morphology of densed nanocrystals observed on the surface of synthesized nanopolymer with the average particles size of $72 \mathrm{~nm}$ respectively and its histogramis shown in Fig. 9. (I). Figure 9. (m-o) shows the image of PAAQ at $50^{\circ} \mathrm{C}$. It is confirmed from the fact that when increasing the temperature from $40-50^{\circ} \mathrm{C}$, there is an irregular augmentation of nanocrystals which are combined together to provide a interaction between the crystals formed on the nanopolymer surface with the average particles size of $80 \mathrm{~nm}$ respectively and its corresponding histogramis shown in Fig. 9. (p). This may be due to the formation of shear forces occurred during the drying process followed by the cleavage of layers at a particular orientation on the polymer structure. Hence the structural morphology and the particles size of PAAQ polymers have changed with the change of temperature from $25-50^{\circ} \mathrm{C}$.

\subsection{Electrochemical Properties: Cyclic Voltammetry (CV) and Electrochemical Impedance Spectroscopy (EIS)}

CV and EIS are used to investigate the electrochemical properties of prepared nanopolymers. The electrochemical analyses were carried out using three different electrodes and the active materials were the starting monomers and synthesized polymers which are coated on the graphite sheet of $1 \mathrm{~cm} \times 1 \mathrm{~cm}$ square electrode to act as a functioning electrode whereas $\mathrm{Ag} / \mathrm{AgCl}$ electrode as a reference and platinum as a counter electrode using $1 \mathrm{M} \mathrm{H}_{2} \mathrm{SO}_{4}$ as an electrolyte. $\mathrm{CV}$ was done with the scan rates at $5 \mathrm{mVs}^{-1}$ and EIS plots of PAAQ polymers are shown in Fig. 10. The CV plots have clearly described the oxidation potentials observed at about 0.1 and $0.4 \mathrm{~V} ; 0.2 \mathrm{~V} ; 0.2$ and $0.4 \mathrm{~V} ;-0.1$ and $0.2 \mathrm{~V}$ respectively. The reduction potentials were obtained at around -0.1 and $0.3 \mathrm{~V} ;-0.2 \mathrm{~V} ;-0.2$ and $0.2 \mathrm{~V} ;-0.2$ and $0.2 \mathrm{~V}$ for monomer and nanopolymers at 25,40 and $50^{\circ} \mathrm{C}$ respectively. They have shown high intensive two positive current peaks and low negative current cathodic (reduction) peak. The positive current peaks explaining the anodic (oxidation) confirmed the involvement of polymer in catalytic oxidation reactions. The $\mathrm{CV}$ curves were related to the pseudo rectangular shape which might be behaved like electrochemical capacitative due to the presence of heteroatom in the polymer products [15]. Figure 10 provides the ESI analysis for the impedance performance of 1-AAQ monomer and PAAQ polymers respectively. Figure 10. (b,d,f and h) 
has explained the resistance values observed at 7.7, 8.8, 15 and $15 \Omega$ for 1-AAQ monomer and PAAQ respectively.

The electrochemical impedance values have revealed that the monomer and synthesized polymers are showed low conductivity and capacitances. Hence the synthesized nanopolymers have found to exhibit the property of semiconducting which can be used for making semiconducting devices etc. The obtained oxidation potentials were found to be 0.1 and $0.4 \mathrm{~V}$ for monomer, $0.2 \mathrm{~V}$ for PAAQ at $25^{\circ} \mathrm{C}, 0.2$ and $0.4 \mathrm{~V}$ at $40^{\circ} \mathrm{C}$ and -0.1 and $0.2 \mathrm{~V}$ at $50^{\circ} \mathrm{C}$ and the reduction potentials were at -0.1 and $0.3 \mathrm{~V}$ for monomer, $-0.2 \mathrm{~V}$ for PAAQ at $25^{\circ} \mathrm{C},-0.2$ and $0.2 \mathrm{~V}$ at $40^{\circ} \mathrm{C}$ and finally -0.2 and $0.2 \mathrm{~V}$ at $50^{\circ} \mathrm{C}$ respectively. From the results it is concluded that the presence of pseudo behaviour linear electron transfer through the conjugated polymer chain. The electron transfer reaction takes place on the surface of the working electrode used for this experiment. During the reaction the generation of current has changed for each successive polymer system. Among the three polymers synthesized at 25,40 and $50^{\circ} \mathrm{C}$ the polymer at lowest temperature has produced high current generation because of the presence of some defects in the polymer chain in the synthesized polymer at $25^{\circ} \mathrm{C}[16]$.

\subsection{Catalytic conversion performance of polymer samples}

The catalytic conversion of $\mathrm{CO}_{2}$ to $\mathrm{CO}_{3}$ has revealed as complete reaction monitored using simple absorption spectroscopy in the range of $200-400 \mathrm{~nm}$ under optimum conditions. Previous works have indicated the conversion and detection of $\mathrm{CO}_{2}$ gas molecules in atmosphere with the help of nanopolymer as catalyst. $\mathrm{CO}_{2}$ gas has absolutely caused various respiratory problems as well as health issues to human as well as the environment [17]. The initial absorbance values of precursor materials like carbonated water, base solution $(\mathrm{NaOH})$, with and without prepared polymers as a catalyst are shown in Figure. 11 (a) and the effect of absorbance for conversion is depicts in Figure. (b).

From the graph the absorption band at $204 \mathrm{~nm}$ confirms the carbonated water and two new absorption bands have formed at $217\left(\mathrm{HCO}_{3}{ }^{-}\right)$and $238\left(\mathrm{CO}_{3}{ }^{2-}\right) \mathrm{nm}$ confirm the successful conversion of $\mathrm{CO}_{2}$ to $\mathrm{CO}_{3}[18]$. Initially carbon dioxide gas was reacted with water to form carbonic acid $\left(\mathrm{H}_{2} \mathrm{CO}_{3}\right)$ respectively. There is an addition of mixture of $\mathrm{NaOH}$ solution with polymer catalyst and it has taken in the cuvette. From the spectral studies the obtained new band indicates the formation of bicarbonate and carbonate ions [19]. The carbonate ions reacts with sodium ions in $\mathrm{NaOH}$ to form sodium carbonate $\left(\mathrm{Na}_{2} \mathrm{CO}_{3}\right)$ due to the replacement of hydrogen $\left(\mathrm{H}^{+}\right)$ions by sodium $\left(\mathrm{Na}^{+}\right)$ions. The simple catalytic reaction mechanism is given below.

\section{Catalytic mechanism}

During the catalytic conversion reaction using PAAQ at $25^{\circ} \mathrm{C}$ the changes in absorbance is gradually increased from 2.72-3.92 with respective to time interval is due to the formation of carbonate product and it is shown in Figure. 12 (b). Figure 12 (a) shows the change of $\mathrm{pH}$ at different time intervals respectively. During the reaction $\mathrm{pH}$ has gradually changed from acid to base confirmed by the formation of carbonate molecules successfully [20]. The catalytic conversion percentage from $\mathrm{CO}_{2}$ to $\mathrm{CO}_{3}$ at 
different time intervals is shown in Figure. 12 (b). The catalytic conversion rate of $\mathrm{CO}_{2}$ to $\mathrm{CO}_{3}$ is found to be $68.21 \%$ and it is calculated by the formula given below. Hence it is concluded that the prepared polymers acted as very good catalysts to convert unwanted toxic gas into non-toxic product and avoid carbon dioxide risk factors from environment.

$$
A=\left(A_{0}-A_{t} / A_{0}\right) \times 100
$$

Where $A$ is absorbance, $A_{0}$ is initial absorbance and $A_{t}$ is known to be absorbance with time interval.

The as-synthesized polymer at $25^{\circ} \mathrm{C}$ was used for catalytic conversion reaction at room temperature with the time interval of 20 mins using UV spectrophotometer. Figure.13 shows the kinetic performance of synthesized polymer sample. The determination of reaction orders of pseudo-first-order and pseudosecond-order kinetics using the following equations such as (1) and (2) respectively [21]. The kinetic value of rate constant $(K)$ and correlation coefficient $\left(R^{2}\right)$ of catalytic conversion reaction is listed in Table 3. The kinetic models were clearly explained that pseudo-first-order kinetic reaction has obtained highest rate constant $\left(K_{1}=0.0248\right)$ than pseudo-second-order rate constant $\left(K_{2}=0.0081\right)$.

$\ln \mathrm{C}_{\mathrm{o}} / \mathrm{C}=\mathrm{K}_{1} \mathrm{t}(\mathrm{Eq} .1)$

$1 / \mathrm{C}_{\mathrm{t}}-1 / \mathrm{C}_{0}=\mathrm{K}_{2} \mathrm{t}(\mathrm{Eq} .2)$

Where $\mathrm{C}$ is the concentration of the reaction solution, $\mathrm{C}_{0}$ is the initial concentration of the reaction medium, $\mathrm{K}_{1}$ and $\mathrm{K}_{2}$ are the kinetic rate constants with time interval ( $\left.\mathrm{min}\right)$ and $\mathrm{t}$ is the time ( $\left.\mathrm{min}\right)$. The kinetic models have been plotted by using pseudo-first-order and pseudo-second-order rate constant with In $C_{0} / C$ vs time (min) and $1 / C_{t}-1 / C_{0}$ vs time (min). Finally a straight line with the slope of $k_{1}$ and $k_{2}$ has achieved.

Table 3

Kinetic value of rate constant $(K)$ and correlation coefficient $\left(R^{2}\right)$ of catalytic conversion reaction

\begin{tabular}{|lllll|}
\hline Material & \multicolumn{4}{l}{ Catalytic conversion reaction } \\
\cline { 2 - 4 } & \multicolumn{2}{l}{$\begin{array}{l}\text { Pseudo-First-Order Kinetic } \\
\text { Model }\end{array}$} & $\begin{array}{l}\text { Pseudo-Second-Order Kinetic } \\
\text { Model }\end{array}$ \\
\cline { 2 - 4 } & $\mathrm{K}_{\mathbf{1}}(\mathbf{1} / \mathrm{min})$ & $\mathrm{R}^{2}$ & $\mathrm{~K}_{2}(1 / \mathrm{min})$ & $\mathrm{R}^{2}$ \\
\hline PAAQ Polymerat $25^{\circ} \mathrm{C}$ & 0.0248 & 0.9778 & 0.0081 & 0.9599 \\
\hline
\end{tabular}

\subsection{Analysis of PAAQ degradation using LINAC}

Radiation therapy has played vital role in cancer treatment but the usage of extra radiation has caused an effective side effects. The superfluous radiation is to be absorbed or controlled via polymer thin film 
coated chamber around X-ray irradiation. Synthesized nanopolymer was used in the weight range of $0.001 \mathrm{mg}$ placed on the couch of the respective LINAC (Linear Accelerator) which is used for the irradiation. Before the irradiation the sample should be diluted in $1 \mathrm{~mL}$ of acetonitrile solution.

The prepared sample was placed at $100 \mathrm{~cm}$ SSD (Source to Surface Distance) with a field size of $5 \times 5$ $\mathrm{cm}^{2}$ in open mode. The polymers were then directly irradiated with different doses like 10, 20, 30, 40 and 50 Gy (Gray). The OD value was found to be 4.3 for nano PAAQ at $25^{\circ} \mathrm{C}$ before irradiation. During the process the X-ray irradiation has primarily confirmed that the colour of the polymer is changed from light orange to dark red and the colour change was observed with the help of an ultraviolet (UV) chamber. Due to the absorption of $X$-rays the obtained OD values have changed with the optimized temperatures of the synthesized polymers. The increase of irradiated dose leads to decrease of optical density confirms through UV spectroscopy. During the process of X-ray irradiation on polymer the radiation source will be absorbed by the polymer and also it has degraded slightly. The percentage of degradation has calculated using the formula which is given in Sect. 3.9. An effective absorption of radiation has caused the breaking of polymer linkage and reduced the size of polymer macromolecules into micro-molecules. Figure.14 (a) shows the change of polymer from light orange to dark red colour after irradiation. Figure. 14(a-c) show the optical density values and the corresponding X-ray energy doses with percentage of degradation of nano PAAQ during X-ray irradiation. The interaction between X-ray and nano PAAQ have clearly explained that the OD value decreases while increasing the level of source of $X$-ray. The degradation has also happened due to the breaking of polymer chains to produce radicals and reduced the molecular weight of the polymers which lead to the decline of polymer properties.

\section{Conclusion}

Poly(1-aminoanthraquinone) was successfully synthesized by chemical oxidative polymerization method. Nano PAAQs have resulted the effective yield, average particle size in nanoscale, excellent fluorescence emission, remarkable redox potential and good catalytic effect for the conversion of $\mathrm{CO}_{2}$ into $\mathrm{CO}_{3}(68.21 \%$.). The synthesized PAAQ polymers have exhibited good morphology with average particles size at 25,40 and $50^{\circ} \mathrm{C}$ respectively. PAAQ has exhibited emission and excitation bands due to the presence of quinone and benzenoid rings in the polymers. The main scope of the work is the catalytic conversion reaction using synthesized polymer materials and the polymer coated shield has used to protect the penetration of X-rays during the treatment of cancer. Hence, it is concluded that the synthesized nanopolymers must be specifically useful for the fabrication of novel materials for drug delivery system with controlled release in the biomedical fields and semiconducting devices, sensors mainly for environmental cleaning and management systems etc.

\section{Declarations}

\section{Conflict of Interest}

The authors declare that there is no conflict of interest. 


\section{References}

1. Han J, Wang L, Guo R (2012) Reactive polyaniline-supported sub-10 nm noble metal nanoparticles protected by a mesoporous silica shell: controllable synthesis and application as efficient recyclable catalysts. J 22:5932-5935 M Chem,

2. Jiang YB, Kuang CX (2013) Recent advances in the synthesis of 1-monosubstituted 1,2,3-triazoles. Mini-Rev 13:713-719 M Chem,

3. Wu Q, Xu Y, Yao Z, Liu A, Shi G (2010) Super capacitors based on Flexible Graphene/Polyaniline Nanofiber Composite Films. ACS Nano 4:1963-1970

4. Li R, Chen Z, Li J, Zhang C, Guo Q (2013) Effective synthesis to control the growth of polyaniline nanofibers by interfacial polymerization. Synth 171:39-44 Met,

5. Shun Wang Y, Liu Y, Yu J, Du Y, Cui (2013) XiaoweiSonga and Zhiqiang Liang, Conjugated microporous polymers based on biphenylene for $\mathrm{CO}_{2}$ adsorption and luminescent detection of nitroaromatic Compounds. J Name 00:1-3

6. Han Wang B, Lv Z, Tang M, Zhang, WeiqiangGe Y, Liu X, He K, Zhao (2018) XiangpengZheng, Mingyuan $\mathrm{He}$, and Wenbo Bu, Scintillator-Based Nanohybrids with Sacrificial Electron rodrug for Enhanced X-ray-Induced Photodynamic Therapy. Nano Lett 18:5768-5774

7. Xu Y, Jin S, Xu H, Nagai A, Jiang D (2013) Conjugated microporous polymers: design, synthesis and application. Chem 42:8012-8031 S Rev,

8. Li XG, Li H, Huang MR, Moloney MG (2011) Synthesis and multi-functionality of self-stabilized poly(aminoanthraquinone) nanofibrils. J 115:9486-9497 P C C,

9. Li J, Jin P, Tang C (2014) Cr (iii) adsorption by fluorinated activated boron nitride: a combined experimental and theoretical investigation. RSC Adv 4:14815-14821

10. Rose M. Tomno, Julius K. Nzeve, Stephen N. Mailu, Douglas Shitanda and FuchakaWaswa, Heavy metal contamination of water, soil and vegetables in urban streams in Machakos municipality, Kenya, Scientific African, 2020, 9, 1-9.

11. Huang MR, Huang SJ, Li XG (2011) Facile synthesis of polysulfoaminoanthraquinone nanosorbents for rapid removal and ultrasensitive fluorescent detection of heavy metal ions. J 115:5301-5315 P C C,

12. Singh H, Du J, Singh P, Yi TH (2017) Ecofriendly synthesis of silver and gold nanoparticles by Euphrasiaofficinalis leaf extract and its biomedical applications. Artif Cell Nanomed B 46(6):11631170

13. Li XG, Zhang JL, Huang MR (2012) Interfacial synthesis and functionality of self-stabilized polydiaminonaphthalene nanoparticles. Chem 18:9877-9885 J,

14. Shaojun Huang C, Min Y, Liao P, Du H, Sun (2014) Yanqin Zhu and AiminRen, Intrinsically conducting polyaminoanthraquinone nanofibrils: Interfacial synthesis, formation mechanism and lead adsorbents. RSC Adv 4:47657-47669 
15. Razaq A, Nyholm L, Sjodin M, Stromme M, Mihranyan A (2012) Paper-based energy-storage devices comprising carbon fiber-reinforced polypyrrole-cladophoranano cellulose composite electrode. Adv Energy Mater 2:445-454

16. NemindaHarankahawa SandarangheWeerasinghe, Vidanapathirana K, KumuduPerera (2017) Investigation of a Pseudo Capacitor with Polyacrylonitrile based Gel Polymer Electrolyte. J Electrochem Sci Technol 8(2):107-114

17. ShengweiGuoa Hu, Zhang X, Lu H, Xiao, Zhao Y (2018) Sensing carbon dioxide through solution transparency change of gas-responsive polymers. J Mater Chem C 00:1-8

18. Kvasnov BA, Shalaev P, Dolgushin SA, Semeykina VS, Sankova N, Measurement of the Size and Zeta Potential of Polymer Microspheres Using Dynamic Light Scattering and Electrophoretic Light Scattering Methods: Effect of Viscosity of Dispersion Media, IEEE Conference of Russian Young Researchers in Electrical and Electronic Engineering (EIConRus), 2019, 2290-2294. doi:10.1109/eiconrus.2019.8657244

19. AitorSainz Martinez C, Hauzenberger (2018) ApurbaRanjanSahoo, ZitaCsendes, Helmuth Hoffmann and Katharina Bica, Continuous Conversion of Carbon Dioxide to Propylene Carbonate with Supported Ionic Liquids. ACS Sustainable Chem Eng 6:13131-13139

20. QinglingXu S, Lee Y, Cho MyungHwa, Kim (2013) Jean Bouffard and Juyoung Yoon, PolydiacetyleneBased Colorimetric and Fluorescent Chemosensor for the Detection of Carbon Dioxide. J Am Chem Soc 135:17751-17754

21. YasamanPanahianand $\mathrm{N}$, Arsalani (2017) Synthesis of Hedgehoglike $\mathrm{F}-\mathrm{TiO}_{2}(\mathrm{~B}) / \mathrm{CNT}$ Nanocomposites for Sonophotocatalytic and Photocatalytic Degradation of Malachite Green (MG) under Visible Light: Kinetic Study. J Phys ChemA 121:5614-5624

\section{Figures}




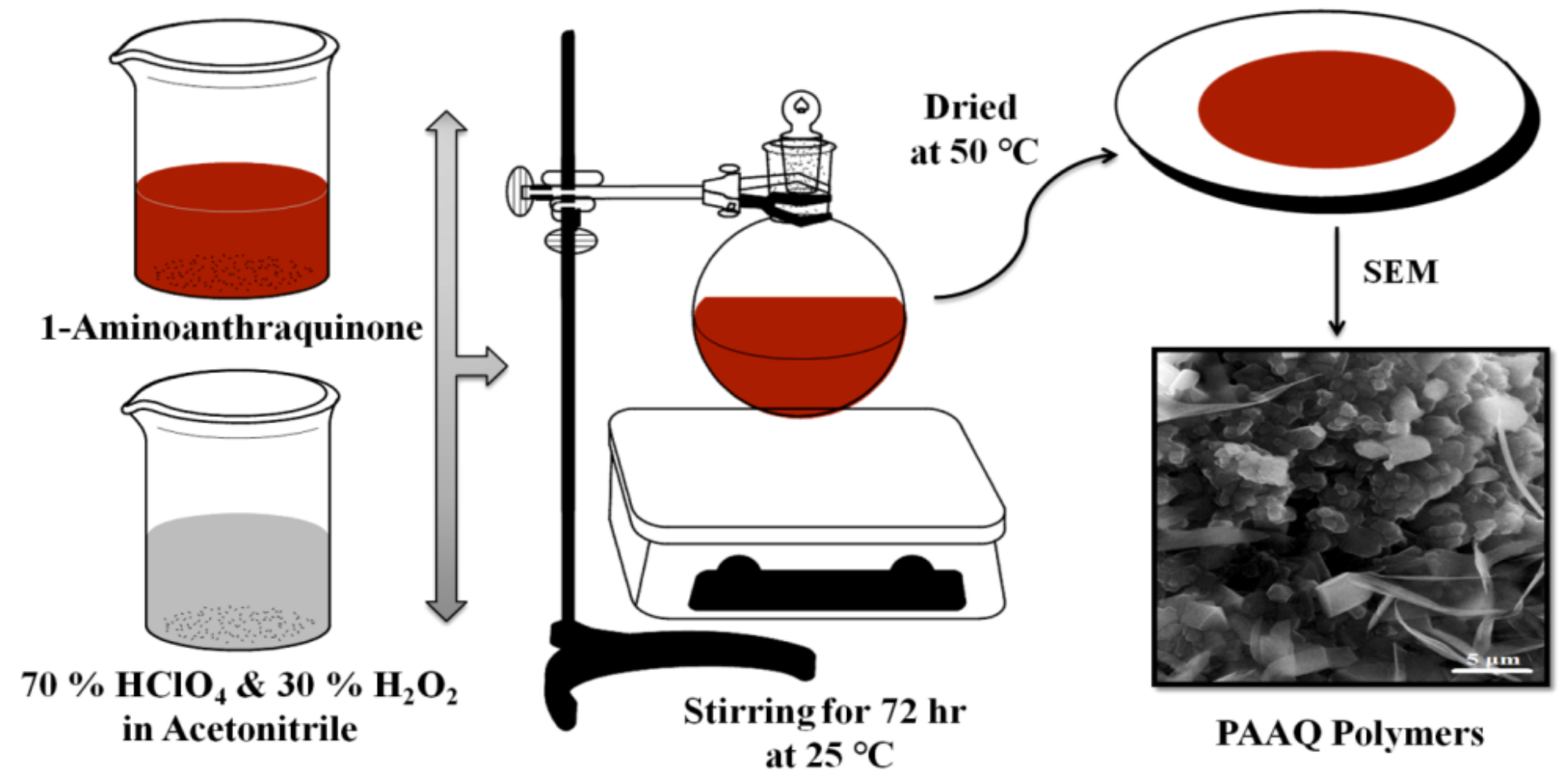

Figure 1

Synthesis of poly(1-aminoanthraquinone)

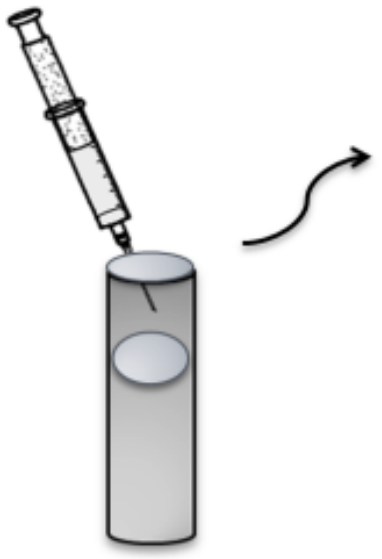

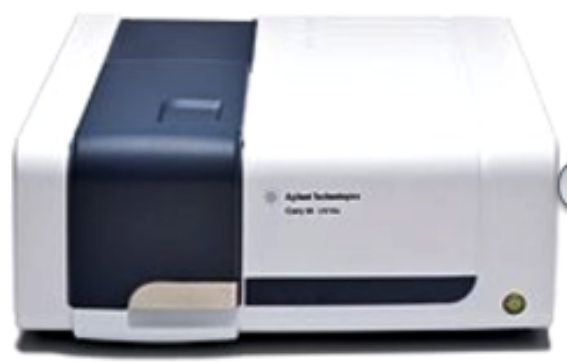

Insert Cuvette in UV

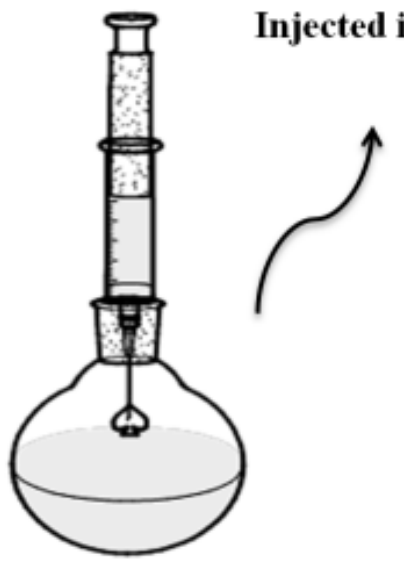

Take Carbonated Water using Syringe

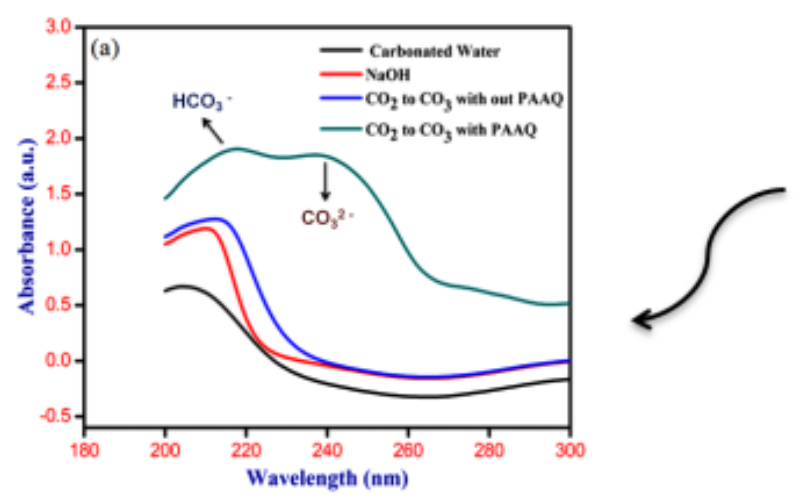

Spectral Data
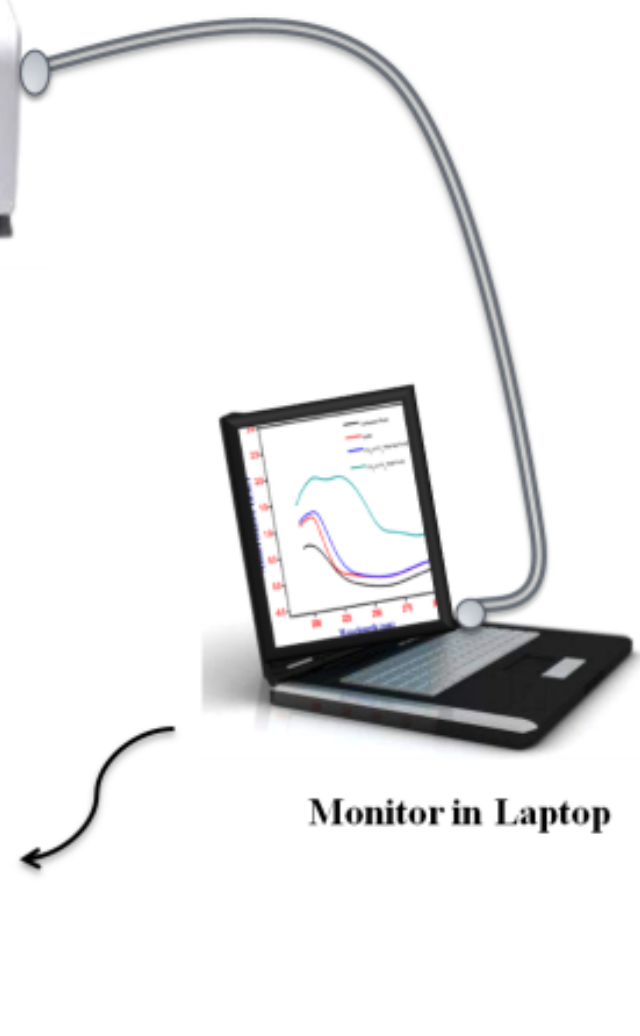
Figure 2

Catalytic conversion of $\mathrm{CO} 2$ to $\mathrm{CO} 3$

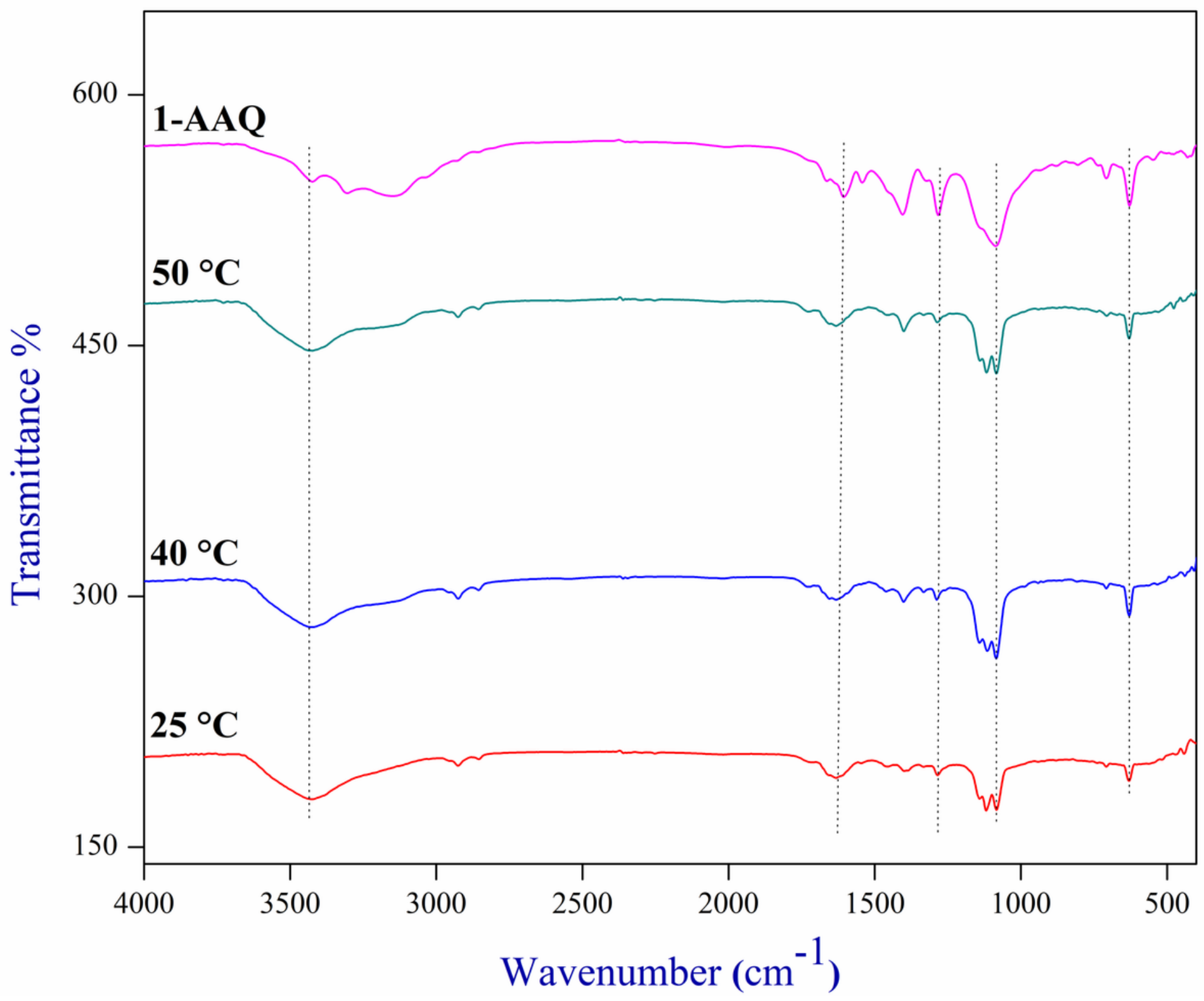

Figure 3

FT-IR spectral studies of monomer and PAAQ 

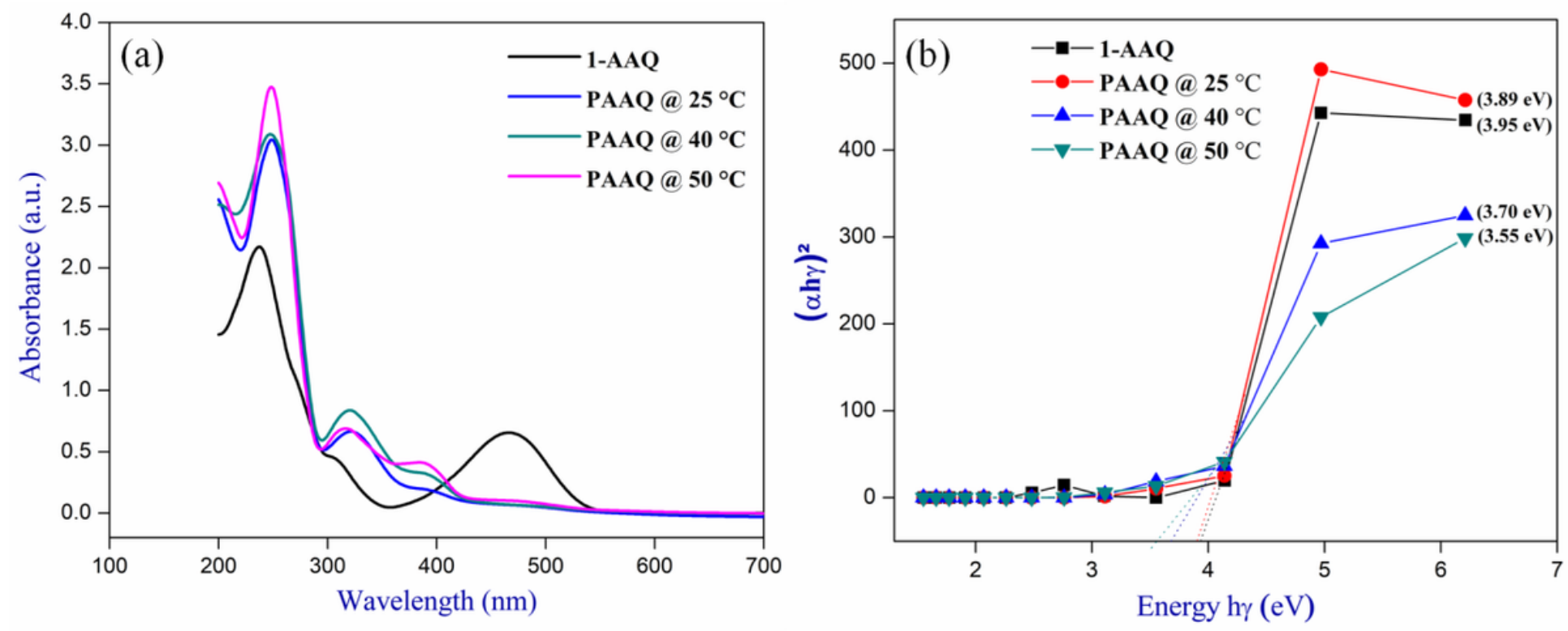

Figure 4

(a) UV-Vis spectra and (b) Tauc plot for PAAQ
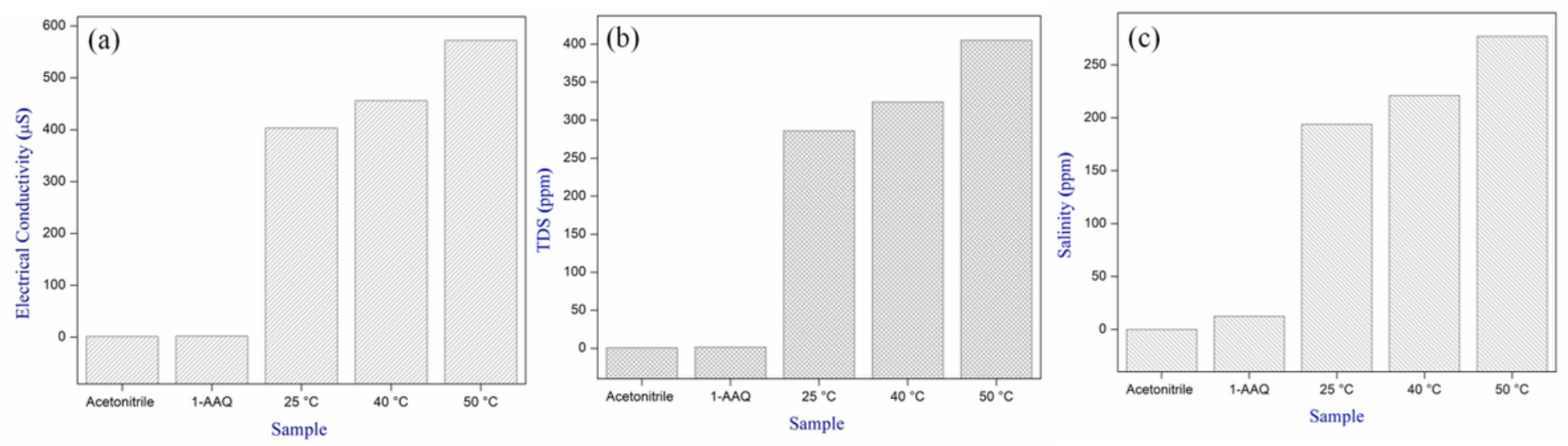

Figure 5

Graphical representation of (a) Electrical conductivity (b) TDS and (c) Salinity 

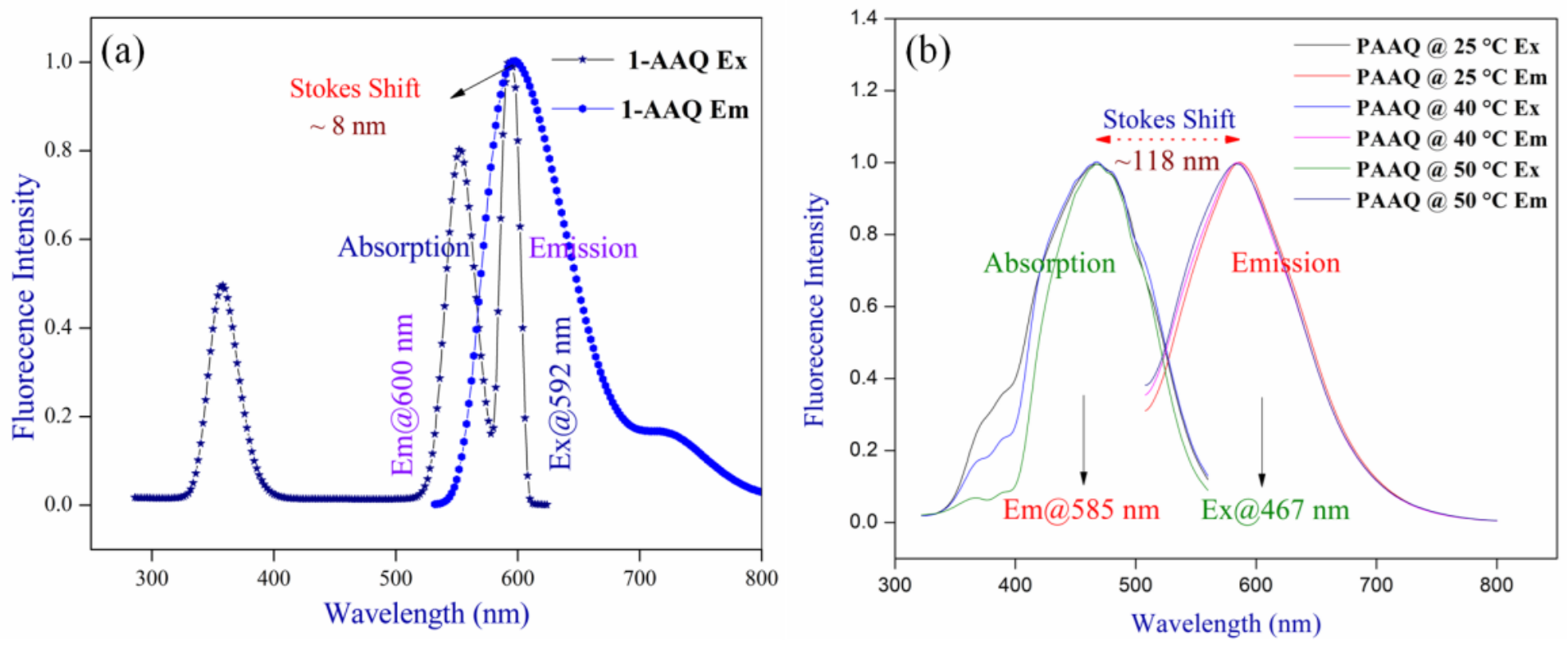

Figure 6

Fluorescent emission and excitation spectra of (a) 1-AAQ and (b) Nano PAAQs
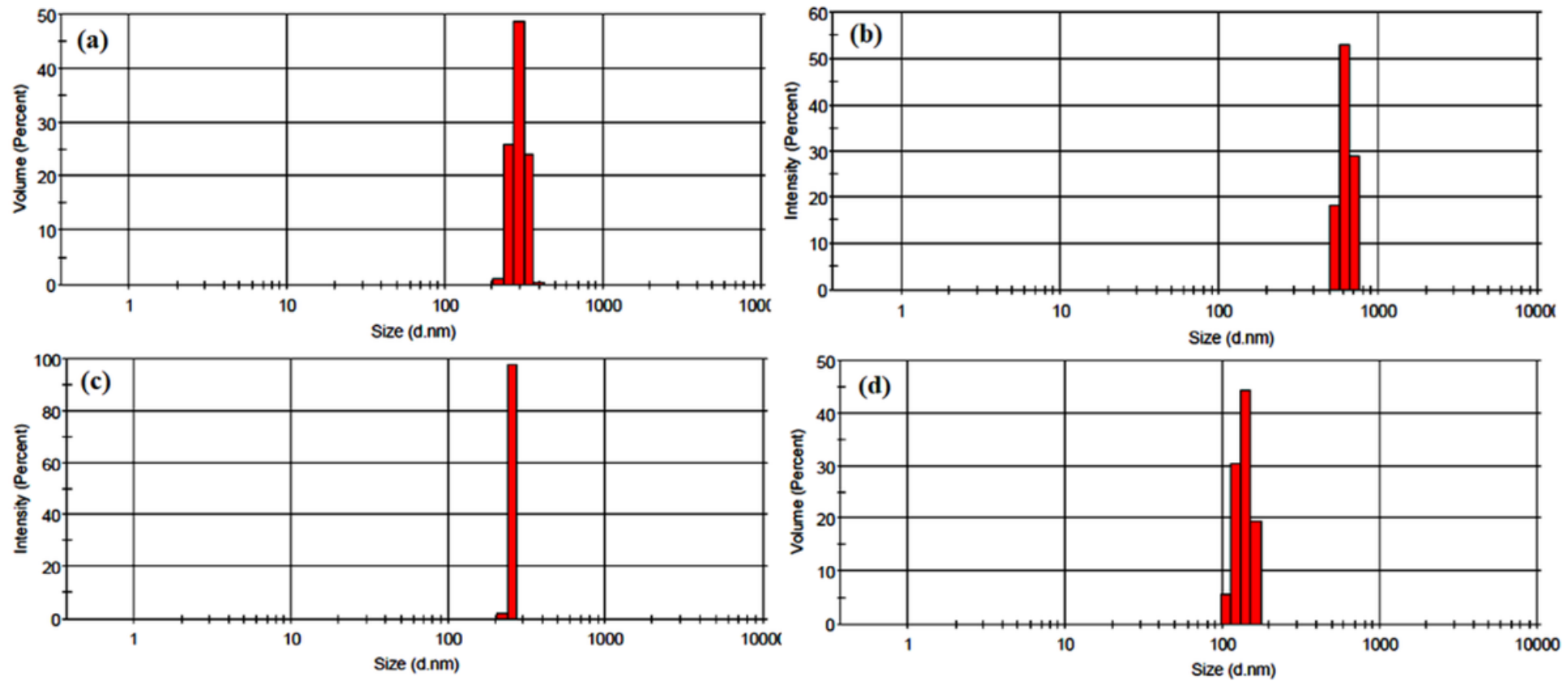

Figure 7

(a-d) Dynamic Light Scattering graphs of 1-AAQ and PAAQ polymers 

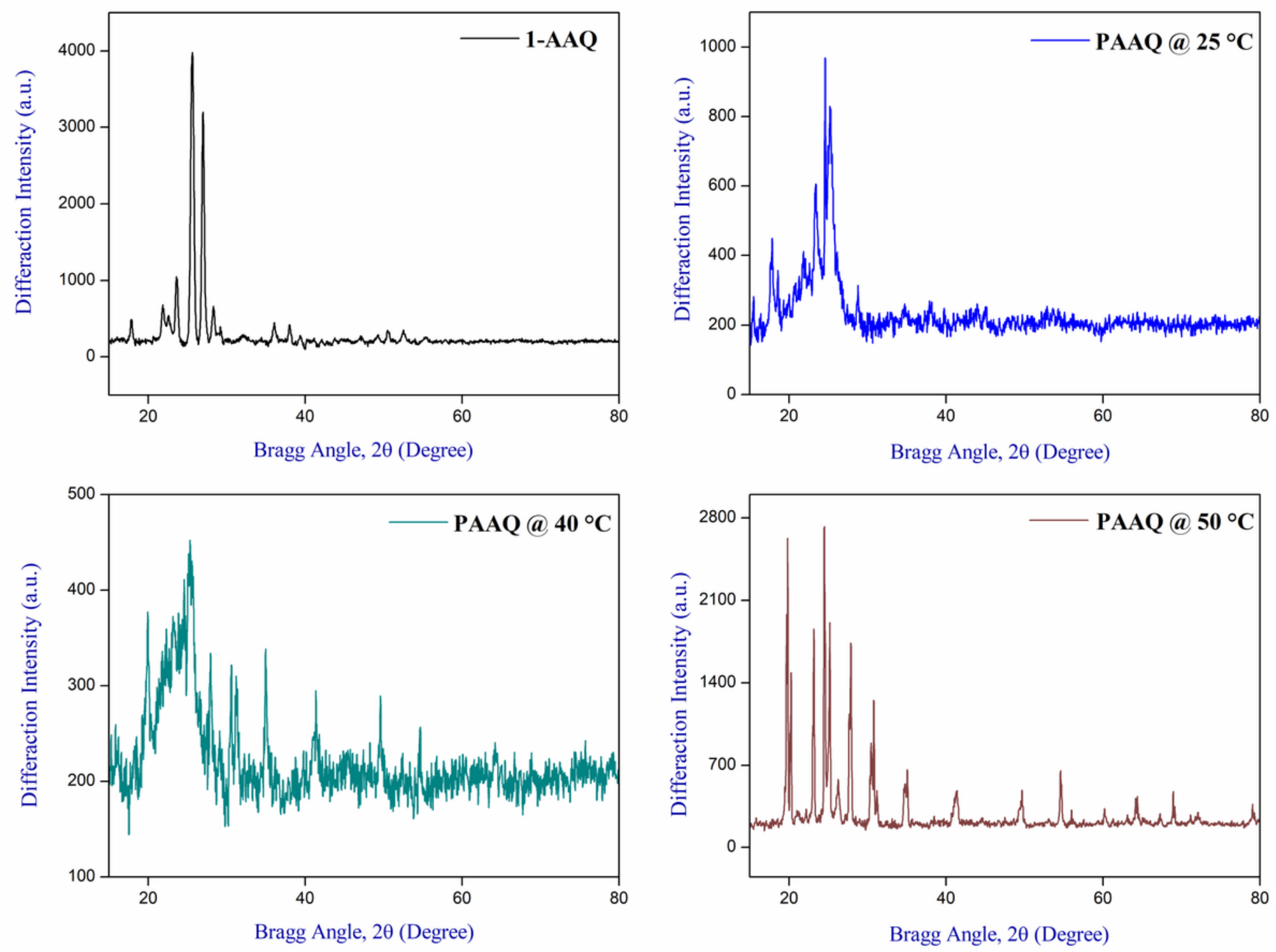

Figure 8

X-ray diffractograms of 1-AAQ and PAAQ 

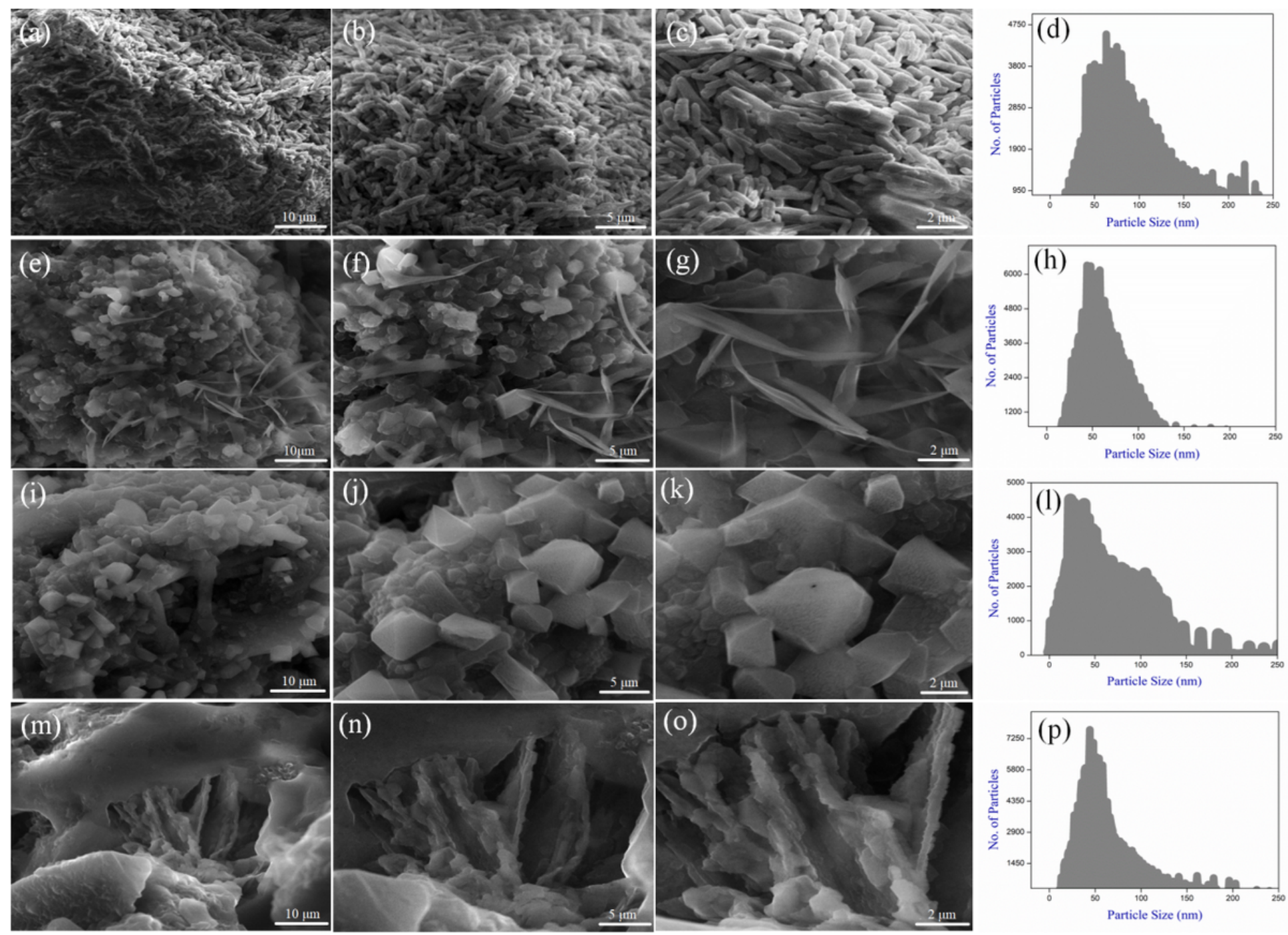

Figure 9

SEM images and average particle size histograms for monomer and synthesized polymers 

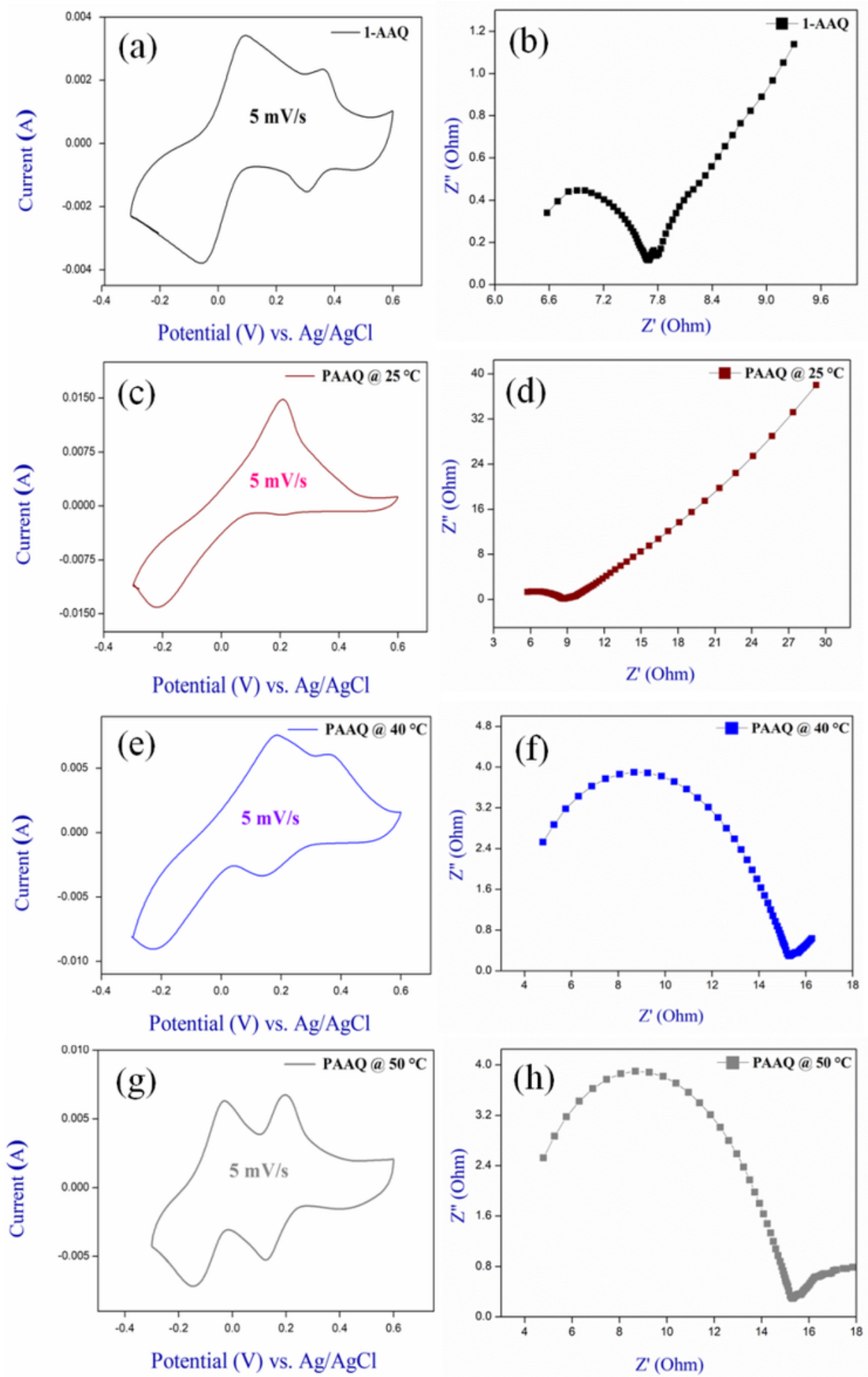

\section{Figure 10}

(a,c,e and g) Cyclic Voltammograms (CV) and (b,d,f and h) and Nyquist plot of monomer and synthesized polymer 

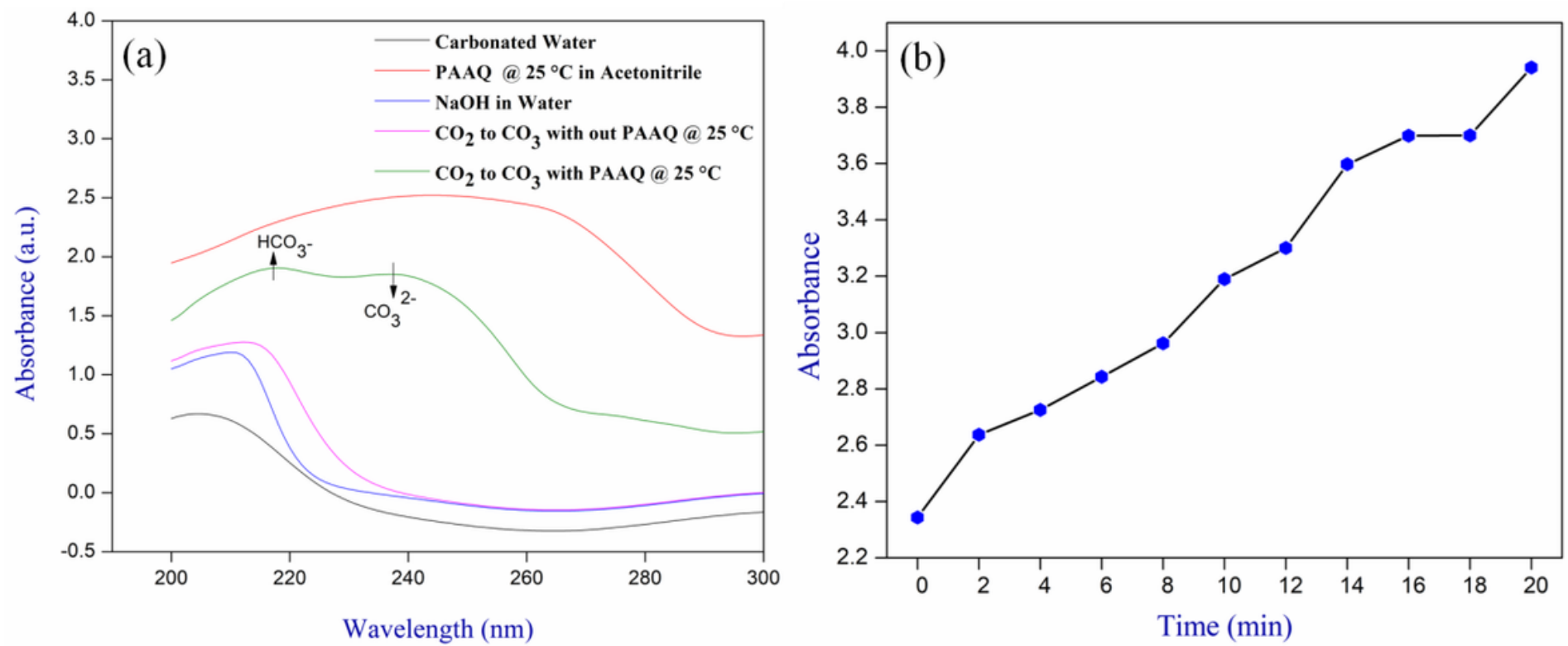

Figure 11

(a) Initial absorption plots for catalytic active materials and (b) Absorbance values for the conversion using PAAQ- $25^{\circ} \mathrm{C}$ 


$$
\begin{aligned}
& \mathrm{CO}_{2}+\mathrm{H}_{2} \mathrm{O} \rightarrow \mathrm{H}_{2} \mathrm{CO}_{3} \\
& \mathrm{H}_{2} \mathrm{CO}_{3} \rightarrow 2 \mathrm{H}^{+}+\mathrm{CO}_{3}^{2-} \\
& \mathrm{NaOH} \rightarrow \mathrm{Na}^{+}+\mathrm{OH}^{-} \\
& 2 \mathrm{Na}^{+}+\mathrm{CO}_{3}^{2-} \rightarrow \mathrm{Na}_{2} \mathrm{CO}_{3}
\end{aligned}
$$
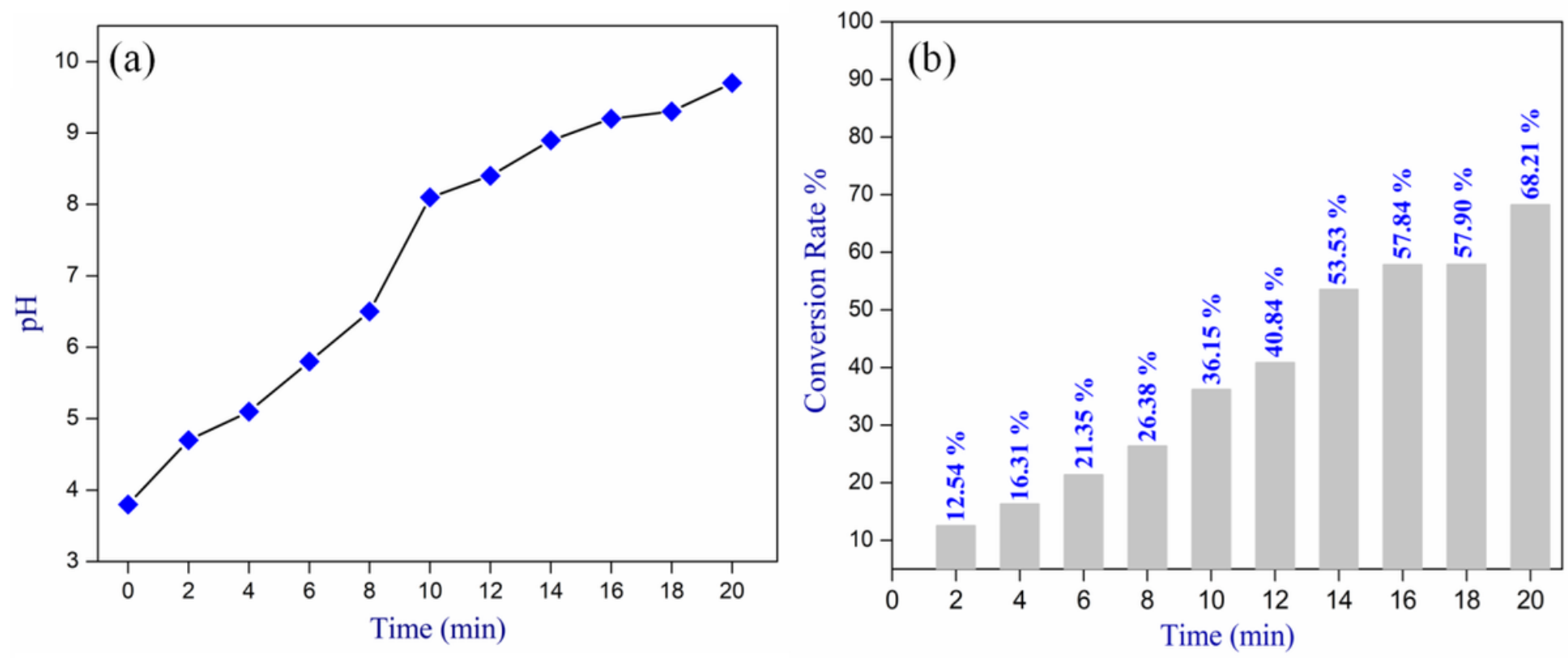

Figure 12

(a) $\mathrm{pH}$ vs. time intervals and (b) Conversion $\%$ of $\mathrm{CO} 3$ using PAAQ $-25^{\circ} \mathrm{C}$
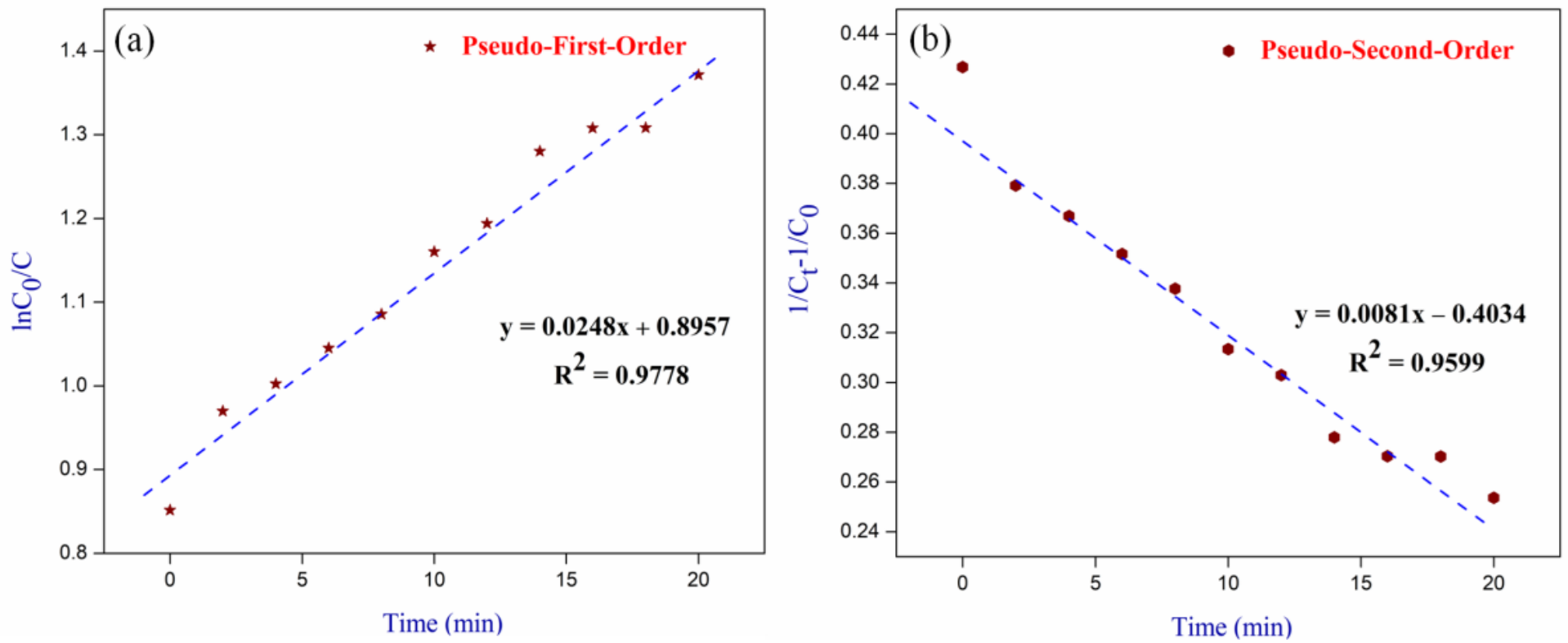


\section{Figure 13}

Kinetic performance of synthesized polymer sample at $25^{\circ} \mathrm{C}$ (a) pseudo-first-order kinetic model and (b) pseudo-second-order kinetic model

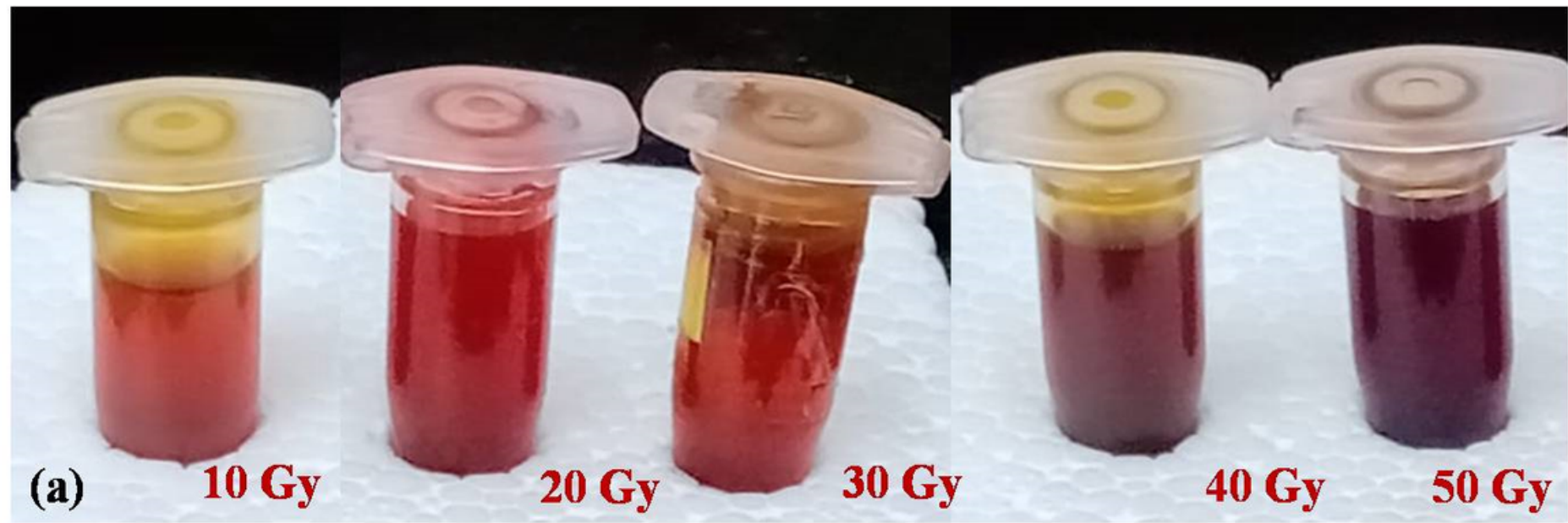

\begin{tabular}{|c|c|c|}
\hline S.No & $\begin{array}{l}\text { X-rays } \\
\text { Doses }\end{array}$ & $\begin{array}{c}\text { Optical Density (OD) } \\
\text { Value }\end{array}$ \\
\hline 1. & $10 \mathrm{~Gy}$ & 3.5 \\
\hline 2. & $20 \mathrm{~Gy}$ & 2.9 \\
\hline 3. & $30 \mathrm{~Gy}$ & 2.6 \\
\hline 4. & $40 \mathrm{~Gy}$ & 2.1 \\
\hline 5. & $50 \mathrm{~Gy}$ & 1.8 \\
\hline
\end{tabular}

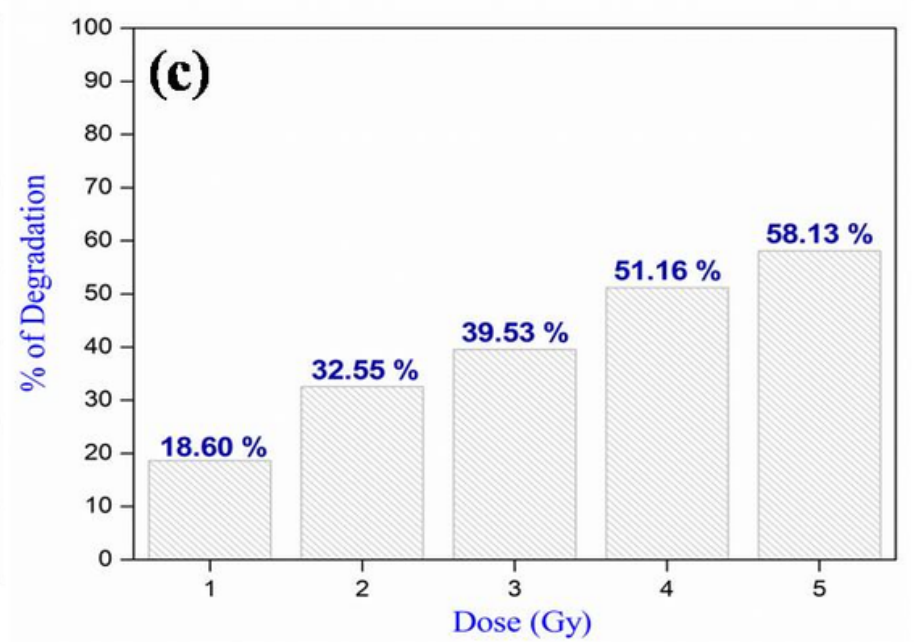

\section{Figure 14}

(a) Various doses of X-ray irradiationto be treated (10-50 Gy) (b) Optical density values using PAAQ and

(c) Percentage of degradation of PAAQ at $25^{\circ} \mathrm{C}$

\section{Supplementary Files}

This is a list of supplementary files associated with this preprint. Click to download.

- Scheme01.png 